\title{
Elevated platelet count is a negative predictive and prognostic marker in locally advanced rectal cancer undergoing neoadjuvant chemoradiation: a retrospective multi-institutional study on 965 patients
}

Claudio Belluco ${ }^{1 *}$ D, Marco Forlin ${ }^{1}$, Paolo Delrio ${ }^{2}$, Daniela Rega ${ }^{2}$, Maurizio Degiuli ${ }^{3,4}$, Silvia Sofia ${ }^{3,4}$, Matteo Olivieri ${ }^{1}$, Salvatore Pucciarelli ${ }^{5}$, Matteo Zuin ${ }^{5}$, Giovanni De Manzoni ${ }^{6}$, Alberto Di Leo ${ }^{6}$, Stefano Scabini ${ }^{7}$, Luigi Zorcolo ${ }^{8}$ and Angelo Restivo ${ }^{8}$

\footnotetext{
Abstract

Background: In patients with locally advanced rectal cancer treated by neoadjuvant chemoradiation, pathological complete response in the surgical specimen is associated with favourable long-term oncologic outcome. Based on this observation, nonoperative management is being explored in the subset of patients with clinical complete response. Whereas, patients with poor response have a high risk of local and distant recurrence, and appear to receive no benefit from standard neoadjuvant chemoradiation. Therefore, in order to develop alternative treatment strategies for non responding patients, predictive and prognostic factors are highly needed. Accumulating clinical observations indicate that elevated platelet count is associated with poor outcome in different type of tumors. In this study we investigated the predictive and prognostic impact of elevated platelet count on pathological response and long-term oncologic outcome in patients with locally advanced rectal cancer undergoing neoadjuvant chemoradiation.

Methods: A total of 965 patients were selected from prospectively maintained databases of seven Centers within the SICO Colorectal Cancer Network. Patients were divided into two groups based on a pre-neoadjuvant chemoradiation platelet count cut-off value of $300 \times 10^{9} / \mathrm{L}$ identified by receiver operating characteristic curve considering complete pathological response as the outcome.

(Continued on next page)
}

\footnotetext{
* Correspondence: cbelluco@cro.it

${ }^{1}$ Department of Surgical Oncology, CRO-IRCCS, National Cancer Institute,

Aviano Via Franco Gallini 2, 33081 Aviano, Italy

Full list of author information is available at the end of the article
}

(c) The Author(s). 2018 Open Access This article is distributed under the terms of the Creative Commons Attribution 4.0 International License (http://creativecommons.org/licenses/by/4.0/), which permits unrestricted use, distribution, and reproduction in any medium, provided you give appropriate credit to the original author(s) and the source, provide a link to the Creative Commons license, and indicate if changes were made. The Creative Commons Public Domain Dedication waiver (http://creativecommons.org/publicdomain/zero/1.0/) applies to the data made available in this article, unless otherwise stated. 
(Continued from previous page)

Results: Complete pathological response rate was lower in patients with elevated platelet count (12.8\% vs. 22.1\%, $p=0.001$ ). Mean follow-up was 50.1 months. Comparing patients with elevated platelet count with patients with not elevated platelet count, 5-year overall survival was $69.5 \%$ vs.76.5\% ( $p=0.016)$, and 5-year disease free survival was $63.0 \%$ vs. $68.9 \%$ ( $p=0.019)$. Local recurrence rate was higher in patients with elevated platelet count (11.1\% vs. $5.3 \%, p=0.001)$, as higher was the occurrence of distant metastasis (23.9\% vs. $16.4 \%, p=0.007)$. At multivariate analysis of potential prognostic factors EPC was independently associated with worse overall survival (HR 1.40, 95\% Cl 1.06-1.86), and disease free survival (HR 1.37, 95\% Cl 1.07-1.76).

Conclusions: In locally advanced rectal cancer elevated platelet count before neoadjuvant chemoradiation is a negative predictive and prognostic factor which might help to identify subsets of patients with more aggressive tumors to be proposed for alternative therapeutic strategies.

Keywords: Platelets, Thrombocytosis, Rectal Cancer, Neoadjuvant chemoradiation, Predictive factors, Prognostic factors, Pathological response, Aspirin,

\section{Background}

In locally advanced (T3-4 or $\mathrm{N}+$ ) mid-distal rectal cancer (LARC), neoadjuvant chemoradiation therapy (CRT) before radical surgery including total mesorectal excision (TME) reduces the risk of local recurrence, and is considered standard treatment [1-3].

However, patients undergoing this multimodality treatment are exposed to the risk of perioperative morbidity and mortality, long-term bowel, bladder, and sexual dysfunction, and permanent colostomy $[4,5]$.

Pathological complete response (pCR) in the surgical specimen is obtained in up to one-third of LARC patients treated by neoadjuvant CRT, and is associated with favourable long-term oncologic outcome [6, 7]. Based on these observations, nonoperative management is being explored in the subset of patients with clinical complete response after CRT [8-11].

On the other hand, LARC patients with poor response to CRT have a high risk of local and distant recurrence, and appear to receive no benefit from standard neoadjuvant CRT.

Therefore, in order to develop alternative treatment strategies both for responding and not responding patients, predictive and prognostic factors are highly needed.

Extensive experimental evidence shows that platelets (PLT) have a crucial role in tumor progression and metastasis through diverse mechanisms, including promotion of epitelial-to-mesenchymal transition, protection of cancer cells from immune surveillance, negotiation of cancer-cell arrest in the micro-vasculature, and stimulation of angiogenesis [12-15]. Moreover, a feed-forward loop wherein tumor and host tissue thrombopoietic cytokines lead to PLT count increasing, which in turn promotes tumor growth, has been demonstrated [16].

Elevated platelet count (EPC) is frequently observed in subsets of patients with cancer, and accumulating clinical observations indicate that thrombocytosis associates with poor outcome in different type of tumors, including colorectal cancer [17-23]. However, at present few studies have examined the predictive and prognostic significance of EPC in rectal cancer undergoing neoadjuvant CRT.

\section{Methods \\ Study design and objectives}

This was a retrospective cohort study aimed to investigate the impact of EPC before neoadjuvant CRT on pCR rate, and long-term oncologic outcome in a large series of LARC patients, consecutively treated in high-volume Referral Centers for Colorectal Surgery, between January 2000 and December 2016. The study was approved by the Institutional Review Board of all participating Centers (coordinating Center ethics committee's reference number CRO-2015-13). All items required by STROBE checklist for reports of observational studies have been included. Clinical and pathological information were retrieved from prospectively maintained electronic databases of 7 Italian Centers from the SICO - Colorectal Cancer Network collaborative study group. The clinical records of selected patients were merged and reviewed.

\section{Study population}

Patients were included in the study if the following criteria were met: histological proved adenocarcinoma of the rectum located up to $12 \mathrm{~cm}$ from the anal verge (AV), pretreatment clinical stage II or III (cT3-4 and or $\mathrm{cN}+$ ), no history of previous cancer, preoperative long course CRT.

The following clinical pretreatment data were considered for both groups: gender; age; distance of the tumor from the anal verge; cTNM stage; time interval between completion of CRT and surgery.

Initial clinical local stage was assessed by pelvic MRI or endorectal ultrasound, alternatively or in combination. Pretreatment staging always included physical examination, colonoscopy, abdominal and chest CT scan. 


\section{Neoadjuvant treatment}

Neoadjuvant treatment included external beam radiotherapy delivered with a total dose of at least 45 Gy administered over 5 weeks (25 fractions of 1.8 Gy/daily) and in most cases with a concomitant boost of 5,4 Gy for a total dose of 50,4 Gy. Concomitant chemotherapy was based on 5-FU either in a daily oral preparation (Capecitabine $1650 \mathrm{mg} / \mathrm{m} 2 / \mathrm{d}$ ) taken during the radiation period, in bolus infusion (5-FU $325 \mathrm{mg} / \mathrm{m} 2 / \mathrm{d} \times 5$ days) during weeks 1 and 5 , or as continuous infusion for 5 days per week over the entire 5 week radiation period (5-FU $250 \mathrm{mg} / \mathrm{m} 2 / \mathrm{d})$.

\section{Outcome measures}

In order to overcome the limitation of the retrospective nature of the study, we selected $\mathrm{pCR}$ as primary endpoint since it is a strong independent prognostic factor of oncologic outcomes and is not affected by confounding factors depending on the subsequent history of the patients, such as for example, adjuvant treatment and time and quality of surgery for metacronous metastasysis.

pCR was defined as absence of any tumour cells at microscopic examination of the resected specimen on final pathology after surgery. Any tumor downstaged to pT0-T1 N0 was defined as good pathological response. All the other histopathological conditions, including partial downstaging were defined as incomplete pathological response.

Overall survival (OS) was calculated as the time from surgical resection to death from any cause, and disease free survival (DFS) was defined as time from surgical resection to tumor recurrence.

\section{Statistical analysis}

Based on pre-neoadjuvant CRT blood samples data, patients were divided in two groups according to a PLT count cut off of $300 \times 10^{9} / \mathrm{L}$. This value was chosen by drawing a receiver operating characteristic (ROC) curve, considering the achievement of $\mathrm{pCR}$ as the outcome, and calculating the maximum level of the relative Youden Index. This corresponded to a PLT count value of $300 \times 10^{9} / \mathrm{L}$ (Sensitivity $54 \%$, Specificity $66 \%$ ).

Difference between the groups were analysed by Fisher exact test for categorical variables, while continuous variables were tested by two independent sample $\mathrm{T}$ tests. Continuous values are expressed in mean and standard deviation.

A multivariate analysis including all available pretreatment data was also performed by binary logistic regression with $\mathrm{pCR}$ as dependent variable. Distance from anal verge and Interval before surgery were transformed into two categorical values before multivariate analysis execution:
- Distance from anal verge $\leq 5 \mathrm{~cm}$ or $>5 \mathrm{~cm}$, because precedent studies had already shown its correlation with pCR; [24]

- Interval before surgery $\leq 8$ weeks or $>8$ weeks, because this cut-off have already shown its correlation with pCR and is currently used in clinical practice as the preferred waiting time lower limit [25].

Kaplan-Meier estimates and log-rank tests were used to assess the association of EPC with OS and DFS. A multivariate analysis for survival was performed by Cox proportional hazards regression, adjusting for sex (male vs. female), age, preoperative primary tumor (cT 1-2 vs. cT3-4) and lymph node (cN0 vs. cN+) stage, type of surgery (anterior resection/Hartmann vs. abdominoperineal resection/proctocolectomy vs. full thickness local excision), pre-CRT platelets count $\left(<300 \times 10^{9} / \mathrm{L}\right.$ vs. $\geq 300 \times$ $\left.10^{9} / \mathrm{L}\right)$, interval to surgery $(\leq 8$ weeks vs. $>8$ weeks $)$, and distance from anal verge $(\leq 5 \mathrm{~cm}$ vs. $>5 \mathrm{~cm})$. To adjust for possible differences within participating centers, this variable was initially included in the multivariate model as a possible confounding variable, and no significant differences were observed. Proportionality of hazards assumption was satisfied by the Schoenfeld residuals method. A $p$ value $<0.05$ was considered statistically significant.

Statistical analysis was conducted using Stata 13.0 software (Stata Statistical Software: Release 13. College Station, TX: Stata Corp LP).

\section{Results}

\section{Patients demographics and EPC distribution}

A total of 965 patients (617 men, 348 women; median age $65 \mathrm{yrs}$ ) were selected for the study. EPC (PLT count $\geq 300 \times 10^{9} / \mathrm{L}$ ) before neoadjuvant CRT was observed in 296 (30.7\%) patients. No significant differences based on EPC status were observed for mean age and variables known to be correlated with $\mathrm{pCR}$, namely distance of the tumour from the anal verge, preoperative stage $\mathrm{T}$ and $\mathrm{N}$, and interval time before surgery. Of notice, EPC was significantly more frequent in female patients (Table 1).

\section{PLT count and pathological response to neoadjuvant CRT}

The main outcome of interest, rate of $\mathrm{pCR}$, resulted significantly lower in patients with EPC (12.84\% vs. $22.12 \%$, $p<0.001)$. This difference was even more evident when considering "good pathological response" as the outcome, $17.43 \%$ in EPC patients compared to $32.99 \%$ in no-EPC patients $(p<0.001)$.

The independent correlation between platelet count and PCR was confirmed by multivariate analysis including other known prognostic factors for pCR (Table 2). 
Table 1 Clinico-pathological and treatment characteristics according to platelets count before neoadjuvant chemoradiation in 965 patients with locally advanced rectal cancer

\begin{tabular}{|c|c|c|c|c|c|}
\hline \multirow[b]{2}{*}{ Variable } & \multicolumn{4}{|l|}{ Platelet count } & \multirow[b]{2}{*}{$p$} \\
\hline & $<300 \times 10^{9} / L$ & & $\geq 300 \times 10^{9} / \mathrm{L}$ & & \\
\hline \multicolumn{6}{|l|}{ Gender } \\
\hline Women & 220 & $32.88 \%$ & 128 & $43.24 \%$ & 0.002 \\
\hline Men & 449 & $67.12 \%$ & 168 & $56.76 \%$ & \\
\hline Age (mean, 95\% Cl) & 64.27 yrs & $63.46-65.08$ & 63.18 yrs & $61.87-64.40$ & 0.155 \\
\hline Distance from anal verge (mean, $95 \% \mathrm{Cl}$ ) & $6.24 \mathrm{cms}$ & $6.04-6.44$ & $5.99 \mathrm{cms}$ & $5.69-6.29$ & 0.169 \\
\hline Interval to surgery (mean, 95\% Cl) & 8.83 weeks & $8.50-9.16$ & 8.75 weeks & $7.99-9.51$ & 0.829 \\
\hline \multicolumn{6}{|l|}{ Clinical primary tumor stage } \\
\hline cT1 & 4 & $0.60 \%$ & 3 & $1.01 \%$ & 0.513 \\
\hline cT2 & 48 & $7.17 \%$ & 22 & $7.43 \%$ & \\
\hline cT3 & 562 & $84.01 \%$ & 239 & $80.74 \%$ & \\
\hline cT4 & 55 & $8.22 \%$ & 32 & $10.81 \%$ & \\
\hline \multicolumn{6}{|l|}{ Clinical lymph node stage } \\
\hline cNO & 254 & $37.97 \%$ & 118 & $39.86 \%$ & 0.576 \\
\hline $\mathrm{cN}+$ & 415 & $62.03 \%$ & 178 & $60.14 \%$ & \\
\hline \multicolumn{6}{|l|}{ Type of surgery } \\
\hline LAR & 515 & $76.98 \%$ & 222 & $75 \%$ & 0.790 \\
\hline APR & 114 & $17.04 \%$ & 58 & $19.59 \%$ & \\
\hline LE & 29 & $4.33 \%$ & 11 & $3.72 \%$ & \\
\hline Other procedures & 11 & $1.64 \%$ & 5 & $1.69 \%$ & \\
\hline \multicolumn{6}{|l|}{ Pathological primary tumor stage (ypT) } \\
\hline урто & 155 & $22.12 \%$ & 41 & $12.84 \%$ & $<0.001$ \\
\hline ypTis & 6 & $0.90 \%$ & 1 & $0.34 \%$ & \\
\hline ypT1 & 74 & $11.06 \%$ & 19 & $6.42 \%$ & \\
\hline ypT2 & 168 & $25.11 \%$ & 91 & $30.74 \%$ & \\
\hline урт3 & 257 & $38.42 \%$ & 130 & $43.92 \%$ & \\
\hline ypT4 & 9 & $1.35 \%$ & 14 & $4.73 \%$ & \\
\hline \multicolumn{6}{|l|}{ Pathological lymph node stage (ypN) } \\
\hline ypNO & 516 & $77.13 \%$ & 211 & $71.28 \%$ & 0.052 \\
\hline ypN+ & 153 & $22.87 \%$ & 85 & $28.72 \%$ & \\
\hline
\end{tabular}

LAR Low anterior resection, APR Abdominoperineal resection, $L E$ full thickness local excision

Table 2 Multivariate analysis (Binary Logistic Regression) using complete pathological response (pCR) to neoadjuvant chemoradiation as dependent variable in 965 patients with locally advanced rectal cancer

\begin{tabular}{lllll}
\hline & Reference & Odds Ratio & $(\mathrm{Cl} 95 \%)$ & $0.98-1.01$ \\
\hline Age & & 0.99 & $0.80-1.56$ & 0.497 \\
Sex & Female & 1.11 & $0.34-0.99$ & 0.533 \\
CT & I-I & 0 & 0.58 & $0.75-1.46$ \\
CN & $<300 \times 10^{9} / \mathrm{L}$ & 1.05 & 0.045 \\
Platelets count & $<5 \mathrm{cms}$ & 0.51 & 0.75 & 0.797 \\
Distance from anal verge & $<8$ weeks & 1.48 & $1.06-2.08$ & 0.001 \\
Interval between CRT and Surgery & 1.35 & $0.93-1.97$ & 0.115 \\
\hline
\end{tabular}

CT Clinical primary tumor stage, $C N$ Clinical lymph node stage, $C R T$ chemoradiation 


\section{Long-term oncologic outcome according to pathological response and PLT count}

Mean follow-up for the entire patient population was 50.1 ( \pm 1.1$)$ months and it was comparable between EPC and no-EPC patients $(51.6 \pm 2.0$ months, and $49.5 \pm$ 1.3 months).

According to pathological response, 5-year OS was $86.1 \%$ for pCR patients compared to $71.5 \%$ for no-pCR patients $(p=0.002)$, and 5-year DFS was 81.9 and 63.8\%, respectively $(p<0.001)$.

Local recurrence rate was significantly higher in EPC patients $(11.15 \%$ vs. $5.38 \%, p=0.001)$, as higher was the chance of distant relapse ( $23.9 \%$ vs. $16.4 \%, p=0.007)$.

This translated also in a significantly worse survival outcome for these patients. Five-year OS was $69.5 \%$ for EPC patients compared to $76.5 \%$ for no-EPC patients ( $p$ $=0.016$ ), and 5-year DFS was 63.0\% and 68,9\%, respectively $(p=0.019)$ (Fig. 1).

At multivariate analysis, after adjusting for other potential prognostic factors EPC was independently associated with worse OS (HR 1.40, 95\% CI 1.06-1.86), and DFS (HR 1.37, 95\%CI 1.07-1.76). (Table 3).

\section{Discussion}

In the present study, we investigated the significance of platelet counts before neoadjuvant CRT in 965 LARC patients. To the best of our knowledge, this is the largest series published in the literature on this specific matter. Our findings indicate that EPC before treatment is a negative predictive and prognostic factor in patients with rectal cancer submitted to CRT.

The prevalence of EPC reported in studies on colorectal cancer patients varies between 8.0 and $49.8 \%$ depending on the defined cut-off. We decided to propose our own cut off value as it is still difficult to define a single best cut-off value for platelet count to be considered normal and or safe.

As reported in a recent meta-analysis, including studies investigating the prognostic significance of pretreatment platelet count in patients with colorectal cancer, the considered cut-off value varies from as low as $267 \times$ $10^{9} / \mathrm{L}$ to as high as $450 \times 10^{9} / \mathrm{L}$, with the value of $300 \times$ $10^{9} / \mathrm{L}$ being the minimum limit to maintain a statistically significance [26].

In this regard our study, being the largest published until now on this topic, actually serves to confirm an important prognostic significance of platelet count as well as to propose a shared cut-off value to use in clinical practice for identification of a subgroup of at risk patients.

In our data the prevalence of EPC (defined in this study as platelet count $\geq 300 \times 10^{9} / \mathrm{L}$ ) was $30.7 \%$. Interestingly, in our cohort of patients EPC was significantly more frequent in female patients. Similar findings have been reported by others [27, 28], and could be explained by the notion of baseline platelet counts and reactivity being higher in women compared to men [29-31]. However, the molecular mechanism of this biological phenomenon is not known.

Multivariate analysis showed that low platelet count before neoadjuvant CRT was an independent positive predictive factor for $\mathrm{pCR}$, with an odd ratio of 1.92 (CI 95\% 1.30-2.83). Our results are consistent with the data reported by others. Kim et al. in a series of 314 patients with locally advanced rectal cancer found that $\mathrm{PCR}$ was achieved in $3.0 \%$ of patients with pre-CRT platelets count $\geq 370 \times 10^{9} / \mathrm{L}$ compared to $14.4 \%$ of patients with platelets count $<370 \times 10^{9} / \mathrm{L} \quad(p=0.01)$. Moreover, at multivariate analysis EPC was an independent negative predictive factor for pCR with an odd ratio of 5.48 [32]. Lee et al. recently reported in 291 consecutive LARC patients that, using a PLT count cut off value of $370 \times 10^{9}$ / $\mathrm{L}$ measured before CRT, pCR was achieved in $4.8 \%$ of the 41 cases with EPC compared to $20.8 \%$ of the 250 cases with not EPC $(P<0.05)$ [33]. In addition, Steele et al. in a small study set of 51 patients with stage II and III rectal adenocarcinoma receiving neoadjuvant CRT, found that patients with PLT counts $<300 \times 10^{9} / \mathrm{L}$ were significantly more likely to exhibit a good or complete pathological response. (42.3\% vs. $12,0 \% ; P=0.015$ ) [34].

The results of our univariate and multivariate survival analysis supports the evidence that EPC associates with poor oncologic outcome in LARC patients undergoing neoadjuvant CRT. In our series, comparing patients with EPC with not EPC the 5-year OS was $69.5 \%$ vs. $76.5 \%$ ( $p$ $=0.016)$, and the 5 -year DFS was $63.0 \%$ vs. $68.9 \%$ ( $p=$ $0.019)$. Kim et al. in their study on 314 rectal cancer patients reported that the 3-year OS and DFS rates in EPC patients were significantly lower than that of no-EPC patients $(81.2 \%$ vs. $96.2 \%$; $p=0.001$ and $62.9 \%$ vs. $76.1 \%$; $p=0.037$ ) [32]. Wan et al. using a cohort of 1513 surgically resected colorectal cancer patients (447 rectum), reported that EPC $\left(\geq 400 \times 10^{9} / \mathrm{L}\right)$ measured within 1 month before surgery was an independent negative prognostic factor of OS $(\mathrm{HR}=1.66 ; 95 \% \mathrm{CI}=1.34-2.05$; $\left.p=2.6 \times 10^{-6}\right)$, and of distant recurrence $(\mathrm{HR}=2.81$; $95 \%$ CI $=1.67-4.74, p=1.1 \times 10^{-4}$ ) [35]. Similarly, Sasaki et al. reported, in a study on 636 colorectal cancer patients $\left(222\right.$ rectum), that preoperative EPC $\left(>370 \times 10^{9} /\right.$ L) was an independent negative prognostic factor of disease specific survival (HR 3.04; 95\% CI 1.82-4.96; $p<$ 0.001) [27]. Cravioto-Villanueva et al. reported in a study on 163 rectal cancer patients that preoperative high platelets count associated with poor OS ( $\mathrm{p}<0.001)$ [36]. In a study on 629 patients (341 rectum), Nyasavajjala et al. found no difference at multivariate analysis in OS based on preoperative thrombocytosis. In this retrospective study however, the platelets count cut off was 
a

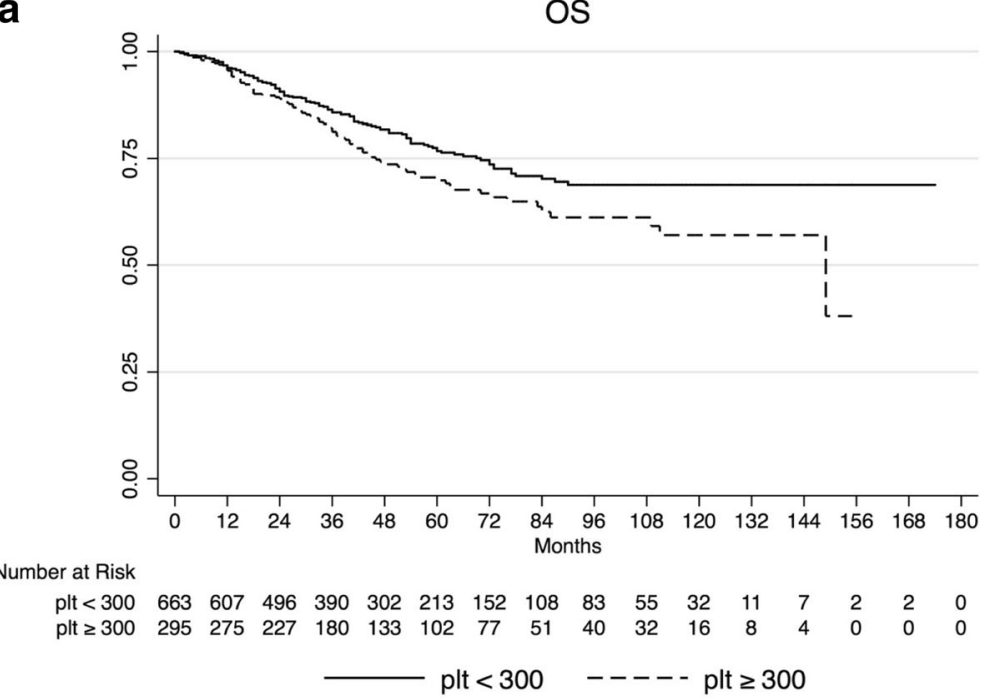

b

DFS

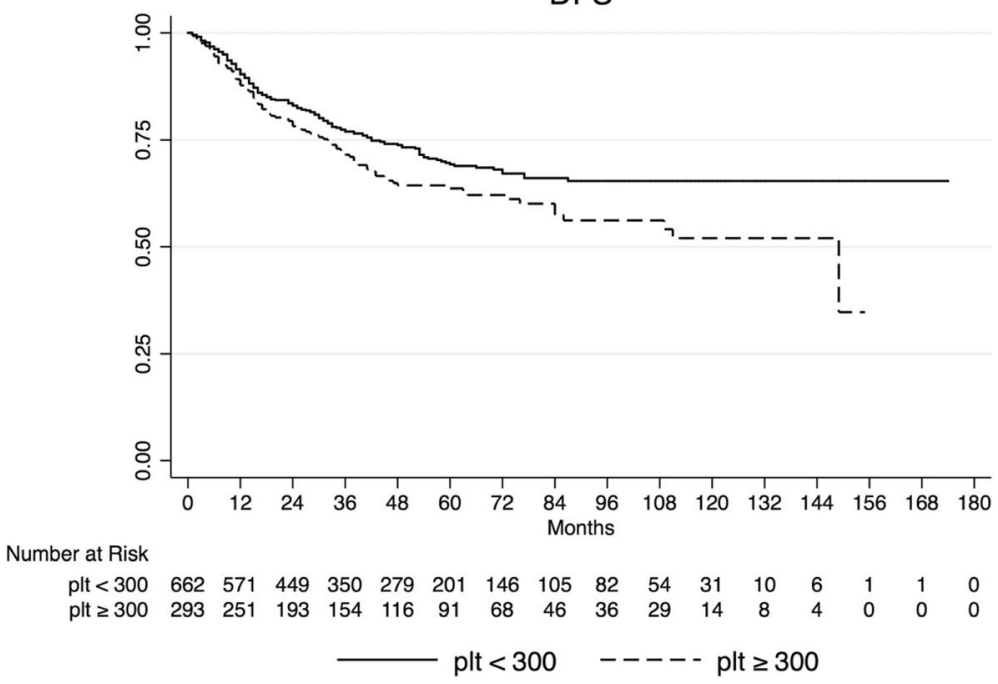

Fig. 1 Kaplan-Meier estimates for overall survival (OS) (a), and disease-free survival (DFS) (b) according to platelet count before neoadjuvant chemoradiation in 965 patients with locally advanced rectal cancer

Table 3 Multivariate analysis of prognostic factors in 965 patients with locally advanced rectal cancer undergoing neoadjuvant chemoradiation

\begin{tabular}{|c|c|c|c|c|c|c|c|}
\hline & \multicolumn{4}{|l|}{ Overall Survival } & \multicolumn{3}{|c|}{ Disease-Free Survival } \\
\hline & Reference & $\mathrm{HR}$ & (Cl 95\%) & $p$ & $\mathrm{HR}$ & (Cl 95\%) & $p$ \\
\hline Age & & 1.04 & $1.03-1.06$ & 0.000 & 1.03 & $(1.01-1.04)$ & 0.000 \\
\hline Sex & Female & 0.79 & $0.59-1.06$ & 0.113 & 0.82 & $(0.63-1.06)$ & 0.127 \\
\hline cT & $|-| \mid$ & 1.58 & $0.88-2.84$ & 0.127 & 1.18 & $(0.74-1.88)$ & 0.495 \\
\hline $\mathrm{cN}$ & 0 & 0.93 & $0.71-1.23$ & 0.634 & 1.07 & $(0.84-1.37)$ & 0.57 \\
\hline Platelets count & $<300 \times 10^{9} / \mathrm{L}$ & 1.45 & $1.10-1.92$ & 0.009 & 1.39 & $(1.09-1.79)$ & 0.009 \\
\hline Distance from anal verge & $<5 \mathrm{cms}$ & 0.62 & $0.47-0.81$ & 0.001 & 0.59 & $(0.46-0.75)$ & 0.000 \\
\hline Interval between CRT and Surgery & $<8$ weeks & 1.04 & $0.78-1.38$ & 0.798 & 1.18 & $(0.91-1.54)$ & 0.213 \\
\hline
\end{tabular}

$H R$ hazard ratio, $C T$ Clinical primary tumor stage, $C N$ Clinical lymph node stage, $C R T$ chemoradiation 
set at $>450 \times 10^{9} / \mathrm{L}$ accounting for a small number of cases with thromboyctosis (8.1\%). Moreover, the tumor site (colon vs. rectum) was not imputed as a covariate at multivariate analysis so that no conclusion can be inferred about prognosis in rectal cancer [37].

In our study, EPC was associated with a lower $\mathrm{pCR}$ rate, as well as unfavorable long-term oncological outcomes. Some clinical and experimental evidences may help to explain these results. For example, biologically more aggressive tumors have shown the capability of inducing PLT production, which in turn may have an active role in facilitating cancer progression and dissemination by different mechanisms such as protection from immune surveillance, cancer-cell arrest in the micro-vasculature, and neoangiogenesis stimulation [12-15].

The "malicious" role of PLT activity in cancer development might, at least in part, explain the anticancer effect of aspirin use, as proposed in some recent studies. Specific to rectal cancer, a recent prospective non-randomised study looked at the outcome of patients who were taking aspirin during CRT for rectal cancer compared to patients not taking aspirin. Patients in the aspirin arm had a better progression-free survival, mainly driven by a lower incidence of metastasis during follow-up ( $11 \%$ vs. $25 \%, \mathrm{HR}=$ $0.30,95 \% \mathrm{CI}=0.10-0.86$ ). Downstaging of the primary tumour was also increased from 44 to $68 \%(p=0.011)$, representing an absolute increase of 24\% [38].

From a strict prognostic point of view, it is known that rectal carcinomas not responding to $\mathrm{CRT}$, display a more aggressive clinical behavior, expressed by a higher tendency to develop local and distant recurrence [6,7]. This data is confirmed by the results of our survival analysis showing a significant worse oncologic outcome in the subgroup of patients with no-pCR. Since increased PLT production and activation appear to represent a cancer cell evolutionary strategy, even in case an active role of PLT in CRT resistance is not confirmed, PLT count might still be used to early identify a subset of LARC patients with less favorable outcome to be proposed for more aggressive alternative therapeutic strategies possibly including anti-platelet approaches [39].

\section{Conclusions}

With the limitation of a retrospective study, our findings indicate that in LARC patients EPC before neoadjuvant CRT is independently associated with lower pCR rate and worse long-term oncologic outcome. This observation is of potential clinical relevance, since it might help in the selection of patients to be proposed for more aggressive therapeutic strategies, as well as for trials using platelet targeting agents.

\section{Abbreviations}

CRT: Chemoradiation therapy; DFS: Disease free survival; EPC: Elevated platelet count; LARC: Locally advanced rectal cancer; OS: Overall survival;
pCR: Pathological complete response; PLT: Platelets; TME: Total mesorectal excision

\section{Acknowledgements}

The authors would like to thank the Società Italiana di Chirurgia Oncologica (SICO) for supporting the Colorectal Cancer Network collaborative study group activity.

Funding

The authors declare that they have no financial supports on this study.

Availability of data and materials

The datasets used and/or analysed during the current study are available from the corresponding author on reasonable request.

\section{Authors' contributions}

This study was conceived by $C B, P D, M D, S P, A R$, LZ. All substantial contributions are listed as follows: clinical data was collected by MF, DR, SS, MO, MZ, ADL, SS, $A R$; Statistical processing was provided by $A R$; Article was written by $C B$ and $A R$, with $C B$ responsible for the final submitted draft. All authors read and approved this manuscript.

Ethics approval and consent to participate

This study was approved by the Ethics Committee of:

- Centro di Riferimento Oncologico, CRO-IRCCS, Aviano, Italy (Coordinating Center -reference number, CRO-2015-13);

- IRCCS Istituto Nazionale per lo Studio e la Cura dei Tumori Fondazione "G. Pascale", Napoli, Italy;

- Azienda Ospedaliera-Universitaria San Luigi Gonzaga, Orbassano, Torino, Italy;

- Comitato Etico per la Sperimentazione Clinica della Provincia di Padova, Padova, Italy;

- Comitato Etico per la Sperimentazione Clinica della Provincia di Verona, Padova, Italy;

- IRCCS per l'Oncologia, Ospedale Policlinico San Martino, Genova, Italy:

- Azienda Ospedaliero Universitaria di Cagliari, Cagliari, Italy.

Approval for the review of hospital records was obtained from the Ethics Committees of all participating Centers. The requirement for informed consent to participate in this study was waived due to its retrospective design. All patient data were anonymized and de-identified prior to the analysis.

Consent for publication

Not applicable.

\section{Competing interests}

The authors declare that they have no competing interests.

\section{Publisher's Note}

Springer Nature remains neutral with regard to jurisdictional claims in published maps and institutional affiliations.

\section{Author details}

'Department of Surgical Oncology, CRO-IRCCS, National Cancer Institute, Aviano Via Franco Gallini 2, 33081 Aviano, Italy. ${ }^{2}$ Colorectal Surgical Oncology, National Cancer Institute - IRCCS - G. Pascale Foundation, Naples, Italy. ${ }^{3}$ School of Medicine, Department of Oncology, Head, Digestive, University of Torino, Torino, Italy. ${ }^{4}$ Surgical Oncology, San Luigi University Hospital, Orbassano, Torino, Italy. ${ }^{5}$ Department of Surgical, Oncological and Gastroenterological Sciences, University of Padova, Padova, Italy.

${ }^{6}$ Department of Surgery, General and Upper G.I., Surgery Division, University of Verona, Verona, Italy. ${ }^{7}$ Oncologic Surgery and Implantable Systems Unit, Department of Emergency, IRCCS San Martino IST, Genoa, Italy. ${ }^{8}$ Colorectal Surgery Unit, Department of Surgical Sciences, University of Cagliari, Cagliari, Italy. 


\section{Received: 21 March 2018 Accepted: 31 October 2018} Published online: 12 November 2018

\section{References}

1. Bosset J-F, Collette L, Calais G, et al. Chemotherapy with preoperative radiotherapy in rectal cancer. N Engl J Med. 2006;355:1114-23.

2. NCCN Clinical Practice Guidelines in Oncology. Rectal Cancer Version 3. 2017). http://www.nccn.org/professionals/physician_gls/pdf/rectal.pdf. Accessed 19 Sept 2017.

3. van de Velde CJ, Boelens PG, Borras JM, et al. EURECCA colorectal: multidisciplinary management: European consensus conference colon \& rectum. Eur J Cancer. 2014;50:1, e1-1, e34.

4. Borowski DW, Bradburn DM, Mills SJ, Bharathan B, Wilson RG, Ratcliffe AA, et al. Northern region colorectal Cancer audit group (NORCCAG). Volumeoutcome analysis of colorectal cancer-related outcomes. Br J Surg. 2010; 97(9):1416-30. https://doi.org/10.1002/bjs.7111.

5. Paun BC, Cassie S, MacLean AR, Dixon E, Buie WD. Postoperative complications following surgery for rectal cancer. Ann Surg. 2010;251: 807-18.

6. Maas M, Nelemans PJ, Valentini V, et al. Long-term outcome in patients with a pathological complete response after chemoradiation for rectal cancer: a pooled analysis of individual patient data. Lancet Oncol. 2010; 11(9):835-44.

7. Belluco C, De Paoli A, Canzonieri V, Sigon R, Fornasarig M, Buonadonna A, et al. Long-term outcome of patients with complete pathologic response after neoadjuvant chemoradiation for CT3 rectal cancer: implications for local excision surgical strategies. Ann Surg Oncol. 2011;18(13):3686-93. https://doi.org/10.1245/s10434-011-1822-0.

8. Dossa F, Chesney TR, Acuna SA, Baxter NN. A watch-and-wait approach for locally advanced rectal cancer after a clinical complete response following neoadjuvant chemoradiation: a systematic review and metaanalysis. Lancet Gastroenterol Hepatol. 2017;2(7):501-13. https://doi.org/ 10.1016/S2468-1253(17)30074-2.

9. Renehan AG, Malcomson L, Emsley R, Gollins S, Maw A, Myint AS, et al. Watch-and-wait approach versus surgical resection after chemoradiotherapy for patients with rectal cancer (the OnCoRe project): a propensity-score matched cohort analysis. Lancet Oncol. 2016;17(2):174-83. https://doi.org/ 10.1016/S1470-2045(15)00467-2.

10. Barina A, De Paoli A, Delrio P, Guerrieri M, Muratore A, Bianco F, et al. Rectal sparing approach after preoperative radio- and/or chemotherapy (RESARCH) in patients with rectal cancer: a multicentre observational study. Tech Coloproctol. 2017. https://doi.org/10.1007/s10151-017-1665-1.

11. Sammour T, Price BA, Krause KJ, Chang GJ. Nonoperative management or 'Watch and Wait' for rectal Cancer with complete clinical response after neoadjuvant Chemoradiotherapy: a critical appraisal. Ann Surg Oncol. 2017; 24(7):1904-15. https://doi.org/10.1245/s10434-017-5841-3 Epub 2017 Mar 21. PubMed PMID: 28324284.

12. Suzuki-Inoue K. Platelets and cancer: pathology and drug targets. Platelets. 2018;11:1-2. https://doi.org/10.1080/09537104.2018.1512799 [Epub ahead of print] PubMed PMID: 30204046

13. Wojtukiewicz MZ, Sierko E, Hempel D, Tucker SC, Honn KV. Platelets and cancer angiogenesis nexus. Cancer Metastasis Rev. 2017. https:// doi.org/10.1007/s10555-017-9673-1 [Epub ahead of print] PubMed PMID: 28681240

14. Gay LJ, Felding-Habermann B. Contribution of platelets to tumour metastasis. Nat Rev Cancer. 2011;11(2):123-34. https://doi.org/10.1038/ nrc3004 Review.

15. Borsig $L$. The role of platelet activation in tumor metastasis. Expert Rev Anticancer Ther. 2008;8:1247-55.

16. Stone RL, Nick AM, McNeish IA, Balkwill F, Han HD, Bottsford-Miller J, et al. Paraneoplastic thrombocytosis in ovarian cancer. N Engl J Med. 2012;366(7): 610-8. https://doi.org/10.1056/NEJMoa1110352.

17. Bailey SE, Ukoumunne OC, Shephard EA, Hamilton W. Clinical relevance of thrombocytosis in primary care: a prospective cohort study of cancer incidence using English electronic medical records and cancer registry data. Br J Gen Pract. 2017;67(659):e405-13. https://doi.org/10. 3399/bjgp17X691109.

18. Menczer J. Preoperative EPC and thrombocytosis in gynecologic malignancies. Arch Gynecol Obstet. 2017;295(1):9-15. https://doi.org/10. 1007/s00404-016-4212-9.
19. Maráz A, Furák J, Varga Z, Kahán Z, Tiszlavicz L, Hideghéty K. Thrombocytosis has a negative prognostic value in lung cancer. Anticancer Res. 2013;33(4): 1725-9 PubMed PMID: 23564823.

20. Foerster B, Moschini M, Abufaraj M, et al. Predictive and prognostic value of preoperative thrombocytosis in upper tract urothelial carcinoma. Clin Genitourin Cancer. 2017;15(6):e1039-45. https://doi.org/10.1016/j.clgc. 2017.06.003 Epub 2017 Jun 19. PubMed PMID: 28694147.

21. Zhuo Y, Lin L, Zhang M. Pretreatment thrombocytosis as a significant prognostic factor in malignant mesothelioma: a meta-analysis. Platelets. 2016;16:1-7. https://doi.org/10.1080/09537104.2016.1246712.

22. Li YC, Khashab T, Terhune J, Eckert RL, Hanna N, Burke A, Richard AH. Preoperative thrombocytosis predicts shortened survival in patients with malignant peritoneal mesothelioma undergoing operative Cytoreduction and Hyperthermic intraperitoneal chemotherapy. Ann Surg Oncol. 2017; 24(8):2259-65. https://doi.org/10.1245/s10434-017-5834-2 Epub 2017 Mar 21. PubMed PMID: 28324285.

23. Gu D, Szallasi A. Thrombocytosis portends adverse prognosis in colorectal Cancer: a meta-analysis of 5,619 patients in 16 individual studies. AnticanceRes. 2017;37(9):4717-26 Review. PubMed PMID: 28870890.

24. Restivo A, Zorcolo L, Cocco IM, Manunza R, Margiani C, Marongiu L, et al. Elevated CEA levels and low distance of the tumor from the anal verge are predictors of incomplete response to chemoradiation in patients with rectal cancer. Ann Surg Oncol. 2013;20(3):864-71. https://doi.org/10. 1245/s10434-012-2669-8.

25. Kalady M, de Campos-Lobato LF, Stocchi L, Geisler DP, Dietz D, Lavery IC, et al. Predictive factors of pathologic complete response after neoadjuvant Chemoradiation for rectal Cancer. Ann Surg. 2009;250(4):582-9. https://doi. org/10.1097/SLA.0b013e3181b91e63.

26. Long Y, Wang T, Gao Q, Zhou C. Prognostic significance of pretreatment elevated platelet count in patients with colorectal cancer: a meta-analysis. Oncotarget. 2016;7(49):81849-61. https://doi.org/10.18632/oncotarget.13248 Review. PubMed PMID: 27833087: PubMed Central PMCID: PMC5348435.

27. Sasaki K, Kawai K, Tsuno NH, Sunami E, Kitayama J. Impact of preoperative thrombocytosis on the survival of patients with primary colorectal cancer. World J Surg. 2012;36(1):192-200.

28. Ishizuka M, Nagata H, Takagi K, Iwasaki Y, Kubota K. Preoperative thrombocytosis is associated with survival after surgery for colorectal cancer. J Surg Oncol. 2012;106(7):887-91. https://doi.org/10.1002/jso.23163 Epub 2012 May 23. PubMed PMID: 22623286.

29. Segal JB, Moliterno AR. Platelet counts differ by sex, ethnicity, and age in the United States. Ann Epidemiol. 2006;16(2):123-30 Epub 2005 Oct 24. PubMed PMID: 16246584.

30. Biino G, Santimone I, Minelli C, et al. Age- And Sex-Related Variations in Platelet Count in Italy: A Proposal of Reference Ranges Based on 40987 Subjects' Data. Freson K, ed. PLoS ONE. 2013;8(1):e54289. doi:https://doi.org/ 10.1371/journal.pone.0054289.

31. Becker DM, Segal J, Vaidya D, Yanek LR, Herrera-Galeano JE, Bray PF, Moy TF, Becker LC, Faraday N. Sex differences in platelet reactivity and response to low-dose aspirin therapy. JAMA. 2006;295(12):1420-7 PubMed PMID:16551714

32. Kim HJ, Choi GS, Park JS, Park S, Kawai K, Watanabe T. Clinical significance of thrombocytosis before preoperative chemoradiotherapy in rectal cancer: predicting pathologic tumor response and oncologic outcome. Ann Surg Oncol. 2015;22(2):513-9.

33. Lee $\mid H$, Hwang S, Lee SJ, Kang BW, Baek D, Kim HJ, et al. Systemic inflammatory response after preoperative Chemoradiotherapy can affect oncologic outcomes in locally advanced rectal Cancer. Anticancer Res. 2017; 37(3):1459-65.

34. Steele M, Voutsadakis IA. Pre-treatment platelet counts as a prognostic and predictive factor in stage II and III rectal adenocarcinoma. World J Gastrointest Oncol. 2017;9(1):42-9. https://doi.org/10.4251/wjgo.v9.i1.42.

35. Wan S, Lai Y, Myers RE, Li B, Hyslop T, London J, et al. Preoperative platelet count associates with survival and distant metastasis in surgically resected colorectal cancer patients. J Gastrointest Cancer. 2013;44(3):293-304.

36. Cravioto-Villanueva A, Luna-Perez P, Gutierrez-de la Barrera M, MartinezGómez H, Maffuz A, Rojas-Garcia P, et al. Thrombocytosis as a predictor of distant recurrence in patients with rectal cancer. Arch Med Res. 2012; 43(4):305-11.

37. Nyasavajjala SM, Runau F, Datta S, Annette H, Shaw AG, Lund JN. Is there a role for pre-operative thrombocytosis in the management of colorectal cancer? Int J Surg. 2010;8(6):436-8. 
38. Restivo A, Cocco IM, Casula G, Scintu F, Cabras F, Scartozzi M, et al. Aspirin as a neoadjuvant agent during preoperative chemoradiation for rectal cancer. Br J Cancer. 2015;113(8):1133-9. https://doi.org/10.1038/bjc.2015.336.

39. Wojtukiewicz MZ, Hempel D, Sierko E, Tucker SC, Honn KV. Antiplatelet agents for cancer treatment: a real perspective or just an echo from the past? Cancer Metastasis Rev. 2017;36(2):305-29. https://doi.org/10.1007/ s10555-017-9683-z

Ready to submit your research? Choose BMC and benefit from:

- fast, convenient online submission

- thorough peer review by experienced researchers in your field

- rapid publication on acceptance

- support for research data, including large and complex data types

- gold Open Access which fosters wider collaboration and increased citations

- maximum visibility for your research: over $100 \mathrm{M}$ website views per year

At $\mathrm{BMC}$, research is always in progress.

Learn more biomedcentral.com/submissions 